\title{
Management of Complications of Colorectal Submucosal Dissection
}

\author{
Eun Ran Kim and Dong Kyung Chang \\ Division of Gastroenterology, Department of Internal Medicine, Samsung Medical Center, Sungkyunkwan University School of Medicine, \\ Seoul, Korea
}

Endoscopic submucosal dissection (ESD) is a useful procedure for the treatment of superficial gastrointestinal neoplasm. Compared with endoscopic mucosal resection (EMR), ESD has several benefits, which include resectability of various difficult lesion, accurate histologic assessment of specimen, and lower recurrence rate. However, the risk of procedure- related complications is higher with ESD than with EMR. Moreover, because the colon has a thin wall and limited endoscopic maneuverability, ESD is considered a more challenging and risky procedure when performed in the colon than in the stomach. ESD-related complications are more likely to occur. The significant complications associated with ESD are bleeding, perforation, coagulation syndrome and stenosis, most of which can be treated and prevented by endoscopic intervention and preparation. Therefore, it is important to know how to occur and manage the ESD related complication. Clin Endosc 2019;52:114-119

Key Words: Endoscopic submucosal dissection; Colorectal neoplasms; Gastrointestinal bleeding; Intestinal perforation; Complication

\section{INTRODUCTION}

Endoscopic submucosal dissection (ESD) is an important treatment option for early gastric cancer and it has showed excellent outcomes. In recent years, colorectal ESD has been widely used for large benign colorectal tumor and early colorectal cancer.

ESD has more advantages than the conventional endoscopic mucosal resection (EMR). ESD can control the size and shape of the resected lesion by dissecting the submucosal layer using fine endo-electrosurgical knife, and en bloc resection may be performed even in a larger flat neoplasm. Moreover, neoplasms with submucosal fibrosis can be resected. Thus, this procedure can be applied during the resection of com-

Received: March 3, 2019 Revised: March 21, 2019

Accepted: March 21, 2019

Correspondence: Dong Kyung Chang

Division of Gastroenterology, Department of Internal Medicine, Samsung Medical Center, Sungkyunkwan University School of Medicine, 81 Irwon-ro, Gangnam-gu, Seoul 06351, Korea

Tel: +82-2-3410-3409, Fax: +82-2-3410-6983, E-mail: dkchang@skku.edu ORCID: https://orcid.org/0000-0001-8925-4629

cc This is an Open Access article distributed under the terms of the Creative Commons Attribution Non-Commercial License (http://creativecommons.org/ licenses/by-nc/3.0) which permits unrestricted non-commercial use, distribution, and reproduction in any medium, provided the original work is properly cited. plex neoplasms, such as ulcerative non-lifting neoplasms, and recurrent neoplasms. It is also beneficial as it can facilitate a more precise histologic assessment of the resected specimen and result in a lower recurrence rate.

However, ESD is technically challenging procedure, and it has a longer learning curve due to the high demands of technical skills and a longer procedure time compared than EMR. A higher risk of adverse events, such as bleeding and perforation, is associated with ESD compared with EMR. Moreover, the colon has a thin wall and a more limited endoscopic maneuverability due to its confined space, fold/flexure and mobility than the stomach. In relation to these reasons, ESD is considered a more difficult and risky procedure when performed in the colon than in the stomach and procedurerelated complications are more likely to occur.

In this review, the prevention and management of complications related to colorectal ESD were discussed.

\section{BLEEDING}

Bleeding is the most frequent complication of endoscopic procedures and it can lead to serious conditions such as hemorrhagic shock. It can be classified into immediate (intra-pro- 
cedural) or delayed (post-procedural) bleeding. Immediate bleeding is usually defined as active bleeding that developed during the procedure. Delayed bleeding is defined as melena or bloody stools occurring after the completion of endoscopic procedure. ${ }^{1}$ Most immediate bleeding is caused by direct cut in the vessels and it is usually minor and self-limiting and dose not interfere with the continuation of the procedure. The definition of clinically significant bleeding after ESD has not been established, and it is generally defined as melena or hematochezia with a decrease in hemoglobin level $\geq 2 \mathrm{~g} / \mathrm{dL}$ or the need for blood transfusion..$^{2,3}$ Delayed bleeding mainly occurs between 2 and 7 days after the procedure. However, it can occur as late as 2 weeks after the procedure. ${ }^{2,45}$

The bleeding rate associated with ESD ranges from $0 \%$ to $11.9 \%{ }^{2,6}$ According to a recent meta-analysis, the immediate and delayed bleeding rates are $0.75 \%$ (95\% confidence interval [CI], $0.31 \%-1.8 \%$ ) and $2.1 \%$ (95\% CI, $1.6 \%-2.6 \%$ ), respectively. The bleeding rates are lower in Asian countries than in Western countries (Table 1).

Several studies have shown the risk factors of delayed bleeding after colorectal ESD, and various factors, such as prior used of anti-thrombotic agents, hypertension, resection size, sessile type, and occurrence of significant bleeding or more arterial bleeding during the procedure have been associated with an increased risk of delayed bleeding. ${ }^{4,8,9}$ Suzuki et al. have reported that lesions in the cecum cause an increased risk of delayed bleeding compared with lesions in other parts of the colon. ${ }^{10}$ Recent studies have reported that the presence of lesions in the rectum is an independent risk factors of delayed bleeding after colorectal ESD. ${ }^{4,11,12}$ It was conflicting results that the lesions in the right hemi-colon increases the rate of bleeding after endoscopic polypectomy. ${ }^{13}$ Several reports have shown that a lesion size $\geq 40 \mathrm{~mm}$ is a risk factor of delayed bleeding after the procedure. ${ }^{8,11}$

Bleeding during ESD is common and is not considered a complication. Most minor bleeding in small vessels can be treated by contact coagulation with the tip of a knife or co- agulation using hemostatic forceps. ${ }^{14,15}$ Significant bleeding from large vessels must be managed with hemostatic forceps. However, excessive thermal injury to the wall of colon may lead to delayed perforation because the colon has a thin wall. Thus, hemostatic forceps should precisely grasp the target vessels and properly coagulate them. ${ }^{2,16}$ For the treatment of thick arterial bleeding, clips can be used. However, during submucosal dissection, clips can interfere with sequential dissection and clipping should be cautiously performed. To prevent intra-procedural bleeding, the identification and prophylactic coagulation of nonbleeding submucosal vessels are necessary. ${ }^{17}$ For small vessels, intra-procedural bleeding can be prevented by pre-coagulation with a knife with the soft, forced or spray coagulation mode. In addition, it can be enough to slowly cut by swift coagulation, whereas large vessels must be pre-coagulated using hemostatic forceps. ${ }^{17}$

A recent meta-analysis about prophylactic treatment for post polypectomy bleeding has reported that none of the prophylactic therapies including injection of epinephrine, coagulation and mechanical therapy (clips, detachable or endo-loop) were associated with a lower risk of delayed bleeding (after $24 \mathrm{~h}$ from the procedure) compared without the use of prophylactic therapy. ${ }^{18}$ However, another study for large colorectal lesions $(\geq 2 \mathrm{~cm}$ ) has shown that prophylactic clipping decreased the risk of delayed post-polypectomy bleeding. ${ }^{19}$ Recent studies have shown that prophylactic clip closure of mucosal defects reduced the risk of delayed bleeding after colorectal ESD. ${ }^{20,21}$

Therefore, to prevent delayed bleeding, large visible exposed vessels or any remaining visible vessels after a complete resection must be coagulated using hemostatic forceps. In case of a large exposed vessel, clipping can be a useful method to prevent delayed bleeding. In particular, a pulsating large vessel can be observed in the rectum, and for such vessels, clipping is helpful. ${ }^{2}$ After ESD for large colorectal lesion, prophylactic clip closure can be considered for the prevention of delayed bleeding.

Table 1. Meta-Analysis for Rates of Bleeding and Perforation Associated with Colorectal Endoscopic Submucosal Dissection ${ }^{7}$

\begin{tabular}{lccccc}
\hline \multirow{2}{*}{ Adverse events } & Studies, $\boldsymbol{n}$ & Patients/tumors, $\boldsymbol{n}$ & \multicolumn{3}{c}{ Rate (95\% CI), \% } \\
\cline { 4 - 6 } & & & Total & Asian countries & Western countries \\
\hline Immediate & 24 & $2,274 / 2,319$ & $0.75(0.31-1.8)$ & $0.39(0.11-1.3)$ & $3.3(1.4-7.6)$ \\
$\quad$ Bleeding & 98 & $13,291 / 13,498$ & $4.2(3.5-5.0)$ & $3.8(3.1-4.6)$ & $6.6(4.6-9.4)$ \\
Perforation & & & & & $3.9(2.5-5.8)$ \\
Delayed & 80 & $11,079 / 11,260$ & $2.1(1.6-2.6)$ & $1.8(1.4-2.4)$ & $1.2(0.29-4.6)$ \\
Bleeding & 30 & $3,887 / 3,948$ & $0.22(0.11-0.46)$ & $0.18(0.08-0.42)$ & \\
Perforation & &
\end{tabular}

CI, confidence interval. 


\section{PERFORATION}

In contrast to delayed bleeding which is more common in gastric ESD than colorectal ESD, the perforation rate related to colorectal ESD is higher than that associated with stomach ESD because the proper muscle layer of the colon is thinner than that of the stomach and endoscopic maneuverability in the colon is limited. ${ }^{2,15}$ Perforation is classified as immediate (diagnosed by the endoscopic evidence of a definite mural defect with the visualization of an intraperitoneal organ or peritoneal/fat tissue) or delayed (diagnosed after the completion of endoscopic resection by the presence of free air on abdominal plain radiograph or during computed tomography $[\mathrm{CT}]$ scan). ${ }^{1,22}$ Delayed perforation can be divided into two types; invisible intra-procedural perforation which is not identified during the procedure, but is diagnosed by the presence of free air on simple abdominal radiography or CT scan, and true delayed perforation caused by thermal injury during the procedure. Most delayed perforations develop within $14 \mathrm{~h}$ after the procedure. However, some cases of delayed perforation may be confirmed $24 \mathrm{~h}$ after the procedure. ${ }^{2,22}$

The perforation rate associated with colorectal ESD is as high as $1.4 \%-20.4 \%{ }^{23-25}$ According to a recent meta-analysis, immediate and delayed perforation rates were $4.2 \%$ (95\% CI, $3.5 \%-5.0 \%$ ) and $0.22 \%(95 \% \mathrm{CI}, 0.11 \%-0.46 \%)$, respectively. The immediate and delayed perforation rates were lower in Asian countries than in Western countries (Table 1).

Several reports have assessed the risk factors for the occurrence of perforation during colorectal ESD. Larger tumor size, submucosal fibrosis, colonic location, and less experience of ESD operators are the risk factors of perforation during colorectal ESD. ${ }^{24,26}$ Perforations may occur more frequently in the left side of the colon, particularly in the sigmoid colon which is more tortuous than the other parts of the colon and not fixed to the abdominal wall. ${ }^{27,28}$ The cecum is also at high risk of perforation because it is dome-shaped and the vertical axis at the cecum usually approaches the knives. ${ }^{29}$ Therefore, hook knife can be useful in decreasing the risk of perforation at the cecum because the submucosal tissue is hooked with the tip of the knife and cut to the lateral side of the knife.

Most small perforations and minimal extraluminal contamination that occur during the procedure can be successfully treated with the application of endoscopic clips along with antibiotics and fasting. ${ }^{2,730}$ For large perforations, endo-loop with clipping can be used for the closure of perforation. If perforation is not completely closed, emergent surgery should be performed as soon as possible to reduce the risk of pan-peritonitis. ${ }^{2}$ In addition to endoscopically intractable large perforations, generalized peritonitis, ongoing sepsis and aggravation of peritonitis are the indications of surgery. As previously mentioned, because colorectal ESD is a high- risk procedure causing intra-procedural perforation compared with gastric ESD, sufficient preparations for the possibility of perforation, such as good bowel preparation, selection of appropriate scope and knives according to the location and morphology of a tumor, and use of a carbon dioxide insufflator, are necessary before the procedure. A long- lasting submucosal injection agent, such as hyaluronic acid, can be helpful for the prevention of intra-procedural perforation because it thickens the submucosal fluid cushion and sufficiently lifts up the lesion. ${ }^{29,31}$

In true delayed perforation caused by thermal injury, free air cannot be detected by radiography by sealing with the omentum. Therefore, if delayed perforation is suspected based on abdominal pain, fever and increased inflammatory marker levels, abdominal CT should be performed. ${ }^{22}$ In case of delayed perforation caused by thermal injury, emergent surgery is essential because it has a less favorable prognosis. ${ }^{15,22}$ Iwatsubo et al. have shown that the median duration of hospitalization was longer, and abdominal pain score was higher in patients with delayed perforation than in those with intra-procedural perforation. ${ }^{32}$

Perforation of the rectal lesion below the peritoneal reflection may be diagnosed as mediastinal emphysema, subcutaneous emphysema or peri-rectal abscess instead of free air on radiography. Therefore, close monitoring is must be carried out.

\section{POST-ESD COAGULATION SYNDROME}

Coagulation syndrome (CS) is transmural burn syndrome resulting from electrocoagulation injury in the bowel wall after endoscopic treatments including polypectomy, EMR and $\mathrm{ESD}^{22,33,34} \mathrm{CS}$ is clinically diagnosed based on the presence of abdominal tenderness and/or rebound tenderness matched procedure site by transmural burn and localized peritonitis resulting to serosal inflammation, fever, leukocytosis, and elevated C-reactive protein levels without obvious perforation on abdominal radiography and/or CT scan after endoscopic treatment. ${ }^{22,33,34}$

CS is often confused with a true perforation because both are characterized by pain, fever, and leukocytosis. However, it is important to recognize CS which does not usually require surgery and severe CS can progress to delayed perforation.

The incidence rate of post- ESD CS ranges from $4.8 \%$ to $14.2 \%$, which is considerably higher than that of post-polypectomy CS. ${ }^{33-35}$

The previously known risk factors of post-ESD CS are sex, tumor size, procedure time, tumor location and presence 
of submucosal fibrosis. ${ }^{22,33,34,36,37}$ Right side colon is a known risk factor of post-ESD CS, and the cecum is a part that is a higher risk for adverse events related endoscopic procedures, including post-ESD CS than other parts of the colon. ${ }^{22,34,38}$ It is supposed that the cecal wall is thinner than the other parts of colon and air insufflation during the procedure generates a higher pressure in the cecum than in other parts of the colon, thereby increasing vulnerability to injury. ${ }^{22,38}$

Most CS is successfully managed without the need for surgical intervention. The symptoms of the patients with CS usually improve within $24 \mathrm{~h}$ and subside within $96 \mathrm{~h}$ with conservative treatment including hydration, use of broad spectrum anti-biotics and bowel rest. ${ }^{22,36}$ Patients with mild symptoms can be treated only with oral anti-biotics without hospitalization. However, if patient's symptoms do not improve or worsen despite proper medical management, re-evaluation for the possibility of delayed perforation should be immediately carried out.

A recent study has shown that the prophylactic use of anti-biotics in colorectal ESD can reduce the risk of post-ESD $\mathrm{CS}^{39}$ Anti-biotics were administered $1 \mathrm{~h}$ before ESD and then additionally injected every $8 \mathrm{~h}$ twice more, and the prophylactic use of anti-biotics was then associated with decreased C-reactive protein level and abdominal pain. However, because post-ESD CS occurs only in a few patients, the prophylactic use of anti-biotics in high-risk patients compared with all patients may be effective. ${ }^{34}$

The use of long lasting submucosal injection agent may reduce the risk of post-ESD CS by increasing the thickness of the submucosal layer and consequently reducing transmural burn by electrical current. However, there are no studies showing the preventive effect of long lasting submucosal injection agent on post-ESD CS. ${ }^{40,41}$

Recently, Yamasaki et al. have indicated that line- assisted complete clip closure which is a method achieving complete closure of the mucosal defect on the ESD site, can reduce the incidence of post-ESD CS. ${ }^{42}$ However, further studies must be conducted to validate such result. ${ }^{42}$

\section{STENOSIS}

Post ESD stenosis is generally defined as narrowing through which a standard scope fail to advance. ${ }^{15,43}$ The incidence rates of post-ESD stenosis range from $11.6 \%$ to $17.2 \%$ after esophageal ESD and from $0.7 \%$ (17\% in cardiac lesion, $7 \%$ for pyloric lesion) to $2.5 \%$ ( $4.7 \%$ in the upper, $0.36 \%$ in the middle, and $3.8 \%$ in the lower part) after gastric ESD. ${ }^{15,44-48}$

Several reports have shown that sub-circumferential resection $>75 \%$ of the circumference by ESD in the esophagus or stomach (cardia, pylorus) is a major risk factor of stricture. $^{44,47,48}$

However, in case of colorectal ESD, there were only few studies about post ESD stenosis. Recently, Hayashi et al. have reported that the incidence rate of stenosis after colorectal ESD was 0.49\% (4/822 patients) and post ESD stenosis occurred in $11 \%$ of patients with circumferential resection between $\geq 90 \%$ and $<100 \%$, and in two $(50 \%)$ of four patients with circumferential resection of $100 \%{ }^{49}$ Another study including 69 rectal tumors occupying $>75 \%$ of the rectal circumference has shown that the stenosis occurred in $71.4 \%$ of the patients after total circumferential resection and $43.8 \%$ of the patients after $>90 \%$ of circumference resection. ${ }^{50}$

These studies have shown that the circumferential mucosal defect of $>90 \%$ is a significant risk factor of stenosis after colorectal ESD.

Most stenosis after colorectal ESD can be managed by endoscopic balloon dilation, which is the same as esophageal and gastric stenosis after ESD. However, the preventive role of intra-lesional steroid injection or topical steroid application for stenosis after colorectal ESD is not validated thus far. ${ }^{15,49,50}$

\section{CONCLUSIONS}

A higher rate of adverse events is generally observed after colorectal ESD than colorectal EMR or stomach ESD. Bleeding and perforation are the primary complications of colorectal ESD. However, most complications are treated and prevented by endoscopic intervention and preparation. CS is another common complication after colorectal ESD and is important because it resembles a true perforation upon clinical presentation. Thus, it can be misleading. Most CS cases are successfully managed with medical treatment. The occurrence of stenosis is less common in colorectal ESD than in esophageal and gastric ESD. Endoscopic balloon dilatation can be used to manage most cases of stenosis after colorectal ESD.

Conflicts of Interest

The authors have no financial conflicts of interest.

\section{REFERENCE}

1. Russo P, Barbeiro S, Awadie H, Libanio D, Dinis-Ribeiro M, Bourke M. Management of colorectal laterally spreading tumors: a systematic review and meta-analysis. Endosc Int Open 2019;7:E239-E259.

2. Tanaka S, Kashida H, Saito Y, et al. JGES guidelines for colorectal endoscopic submucosal dissection/endoscopic mucosal resection. Dig Endosc 2015;27:417-434. 
3. Cotton PB, Eisen GM, Aabakken L, et al. A lexicon for endoscopic adverse events: report of an ASGE workshop. Gastrointest Endosc 2010;71:446-454.

4. Okamoto K, Watanabe T, Komeda Y, et al. Risk factors for postoperative bleeding in endoscopic submucosal dissection of colorectal tumors. Oncology 2017;93 Suppl 1:35-42.

5. Matsumoto M, Fukunaga S, Saito Y, et al. Risk factors for delayed bleeding after endoscopic resection for large colorectal tumors. Jpn J Clin Oncol 2012;42:1028-1034.

6. Yamamoto K, Michida T, Nishida T, Hayashi S, Naito M, Ito T. Colorectal endoscopic submucosal dissection: recent technical advances for safe and successful procedures. World J Gastrointest Endosc 2015;7:11141128.

7. Akintoye E, Kumar N, Aihara H, Nas H, Thompson CC. Colorectal endoscopic submucosal dissection: a systematic review and meta-analysis. Endosc Int Open 2016;4:E1030-E1044.

8. Kataoka Y, Tsuji Y, Sakaguchi Y, et al. Bleeding after endoscopic submucosal dissection: risk factors and preventive methods. World J Gastroenterol 2016;22:5927-5935.

9. Ogasawara N, Yoshimine T, Noda H, et al. Clinical risk factors for delayed bleeding after endoscopic submucosal dissection for colorectal tumors in Japanese patients. Eur J Gastroenterol Hepatol 2016;28:14071414.

10. Suzuki S, Chino A, Kishihara T, et al. Risk factors for bleeding after endoscopic submucosal dissection of colorectal neoplasms. World J Gastroenterol 2014;20:1839-1845.

11. Chiba H, Ohata K, Tachikawa J, et al. Delayed bleeding after colorectal endoscopic submucosal dissection: when is emergency colonoscopy needed? Dig Dis Sci 2019;64:880-887.

12. Terasaki M, Tanaka S, Shigita K, et al. Risk factors for delayed bleeding after endoscopic submucosal dissection for colorectal neoplasms. Int J Colorectal Dis 2014;29:877-882.

13. Buddingh KT, Herngreen T, Haringsma J, et al. Location in the right hemi-colon is an independent risk factor for delayed post-polypectomy hemorrhage: a multi-center case-control study. Am J Gastroenterol 2011;106:1119-1124.

14. Wong Kee Song LM, Baron TH. Endoscopic management of procedure-related bleeding. Gastrointestinal Intervention 2012;1:43-52.

15. ASGE Technology Committee, Maple JT, Abu Dayyeh BK, et al. Endoscopic submucosal dissection. Gastrointest Endosc 2015;81:1311-1325.

16. Tamaru Y, Oka S, Tanaka S. Prevention and management of spouting bleeding during endoscopic submucosal dissection for large subpedunculated-type colonic tumor. Dig Endosc 2018;30:128-129.

17. Toyonaga T, Nishino E, Man-I M, East JE, Azuma T. Principles of quality controlled endoscopic submucosal dissection with appropriate dissection level and high quality resected specimen. Clin Endosc 2012;45:362374.

18. Park CH, Jung YS, Nam E, Eun CS, Park DI, Han DS. Comparison of efficacy of prophylactic endoscopic therapies for postpolypectomy bleeding in the colorectum: a systematic review and network meta-analysis. Am J Gastroenterol 2016;111:1230-1243.

19. Liaquat H, Rohn E, Rex DK. Prophylactic clip closure reduced the risk of delayed postpolypectomy hemorrhage: experience in 277 clipped large sessile or flat colorectal lesions and 247 control lesions. Gastrointest Endosc 2013;77:401-407.

20. Ogiyama H, Tsutsui S, Murayama Y, et al. Prophylactic clip closure may reduce the risk of delayed bleeding after colorectal endoscopic submucosal dissection. Endosc Int Open 2018;6:E582-E588.

21. Harada $H$, Suehiro $S$, Murakami D, et al. Clinical impact of prophylactic clip closure of mucosal defects after colorectal endoscopic submucosal dissection. Endosc Int Open 2017;5:E1165-E1171.

22. Hirasawa K, Sato C, Makazu M, et al. Coagulation syndrome: delayed perforation after colorectal endoscopic treatments. World J Gastrointest Endosc 2015;7:1055-1061.

23. Tanaka S, Terasaki M, Kanao H, Oka S, Chayama K. Current status and future perspectives of endoscopic submucosal dissection for colorectal tumors. Dig Endosc 2012;24 Suppl 1:73-79.

24. Kim ES, Cho KB, Park KS, et al. Factors predictive of perforation during endoscopic submucosal dissection for the treatment of colorectal tumors. Endoscopy 2011;43:573-578.

25. Saito Y, Uraoka T, Yamaguchi Y, et al. A prospective, multicenter study of 1111 colorectal endoscopic submucosal dissections (with video). Gastrointest Endosc 2010;72:1217-1225.

26. Hong SN, Byeon JS, Lee BI, et al. Prediction model and risk score for perforation in patients undergoing colorectal endoscopic submucosal dissection. Gastrointest Endosc 2016;84:98-108.

27. Takamaru H, Saito Y, Yamada M, et al. Clinical impact of endoscopic clip closure of perforations during endoscopic submucosal dissection for colorectal tumors. Gastrointest Endosc 2016;84:494-502.e1.

28. Imai K, Hotta K, Yamaguchi Y, et al. Preoperative indicators of failure of en bloc resection or perforation in colorectal endoscopic submucosal dissection: implications for lesion stratification by technical difficulties during stepwise training. Gastrointest Endosc 2016;83:954-962.

29. Lee EJ, Lee JB, Choi YS, et al. Clinical risk factors for perforation during endoscopic submucosal dissection (ESD) for large-sized, nonpedunculated colorectal tumors. Surg Endosc 2012;26:1587-1594.

30. Pissas D, Ypsilantis E, Papagrigoriadis S, Hayee B, Haji A. Endoscopic management of iatrogenic perforations during endoscopic mucosal resection (EMR) and endoscopic submucosal dissection (ESD) for colorectal polyps: a case series. Therap Adv Gastroenterol 2015;8:176-181.

31. Fujishiro M, Yahagi N, Nakamura M, et al. Successful outcomes of a novel endoscopic treatment for GI tumors: endoscopic submucosal dissection with a mixture of high-molecular-weight hyaluronic acid, glycerin, and sugar. Gastrointest Endosc 2006;63:243-249.

32. Iwatsubo T, Takeuchi Y, Yamasaki Y, et al. Differences in clinical course of intraprocedural and delayed perforation caused by endoscopic submucosal dissection for colorectal neoplasms: a retrospective study. Dig Dis 2019;37:53-62.

33. Arimoto J, Higurashi T, Kato S, et al. Risk factors for post-colorectal endoscopic submucosal dissection (ESD) coagulation syndrome: a multicenter, prospective, observational study. Endosc Int Open 2018;6:E342-E349.

34. Ito S, Hotta K, Imai K, et al. Risk factors of post-endoscopic submucosal dissection electrocoagulation syndrome for colorectal neoplasm. J Gastroenterol Hepatol 2018;33:2001-2006.

35. Hong MJ, Kim JH, Lee SY, Sung IK, Park HS, Shim CS. Prevalence and clinical features of coagulation syndrome after endoscopic submucosal dissection for colorectal neoplasms. Dig Dis Sci 2015;60:211-216.

36. Cha JM, Lim KS, Lee SH, et al. Clinical outcomes and risk factors of post-polypectomy coagulation syndrome: a multicenter, retrospective, case-control study. Endoscopy 2013;45:202-207.

37. Yamashina T, Takeuchi Y, Uedo N, et al. Features of electrocoagulation syndrome after endoscopic submucosal dissection for colorectal neoplasm. J Gastroenterol Hepatol 2016;31:615-620.

38. Gimeno-Garcia AZ, Quintero E. Post-polypectomy complications: high risk in the cecum. Endoscopy 2014;46:88-89.

39. Lee SP, Sung IK, Kim JH, et al. A randomized controlled trial of prophylactic antibiotics in the prevention of electrocoagulation syndrome after colorectal endoscopic submucosal dissection. Gastrointest Endosc 2017;86:349-357.e2.

40. Ferreira AO, Moleiro J, Torres J, Dinis-Ribeiro M. Solutions for submucosal injection in endoscopic resection: a systematic review and meta-analysis. Endosc Int Open 2016;4:E1-E16.

41. Yandrapu H, Desai M, Siddique S, et al. Normal saline solution versus other viscous solutions for submucosal injection during endoscopic mucosal resection: a systematic review and meta-analysis. Gastrointest Endosc 2017;85:693-699.

42. Yamasaki Y, Takeuchi Y, Iwatsubo T, et al. Line-assisted complete closure for a large mucosal defect after colorectal endoscopic submucosal dissection decreased post-electrocoagulation syndrome. Dig Endosc 
2018;30:633-641.

43. Mizuta H, Nishimori I, Kuratani Y, Higashidani Y, Kohsaki T, Onishi S. Predictive factors for esophageal stenosis after endoscopic submucosal dissection for superficial esophageal cancer. Dis Esophagus 2009;22:626631.

44. Coda S, Oda I, Gotoda T, Yokoi C, Kikuchi T, Ono H. Risk factors for cardiac and pyloric stenosis after endoscopic submucosal dissection, and efficacy of endoscopic balloon dilation treatment. Endoscopy 2009;41:421-426.

45. Takahashi H, Arimura Y, Masao H, et al. Endoscopic submucosal dissection is superior to conventional endoscopic resection as a curative treatment for early squamous cell carcinoma of the esophagus (with video). Gastrointest Endosc 2010;72:255-264, 264.e1-e2.

46. Kim JS, Kim BW, Shin IS. Efficacy and safety of endoscopic submucosal dissection for superficial squamous esophageal neoplasia: a meta-analysis. Dig Dis Sci 2014;59:1862-1869.

47. Kakushima N, Tanaka M, Sawai H, et al. Gastric obstruction after endoscopic submucosal dissection. United European Gastroenterol J 2013;1:184-190.

48. Iizuka H, Kakizaki S, Sohara N, et al. Stricture after endoscopic submucosal dissection for early gastric cancers and adenomas. Dig Endosc 2010;22:282-288.

49. Hayashi T, Kudo SE, Miyachi H, et al. Management and risk factor of stenosis after endoscopic submucosal dissection for colorectal neoplasms. Gastrointest Endosc 2017;86:358-369.

50. Ohara Y, Toyonaga T, Tanaka S, et al. Risk of stricture after endoscopic submucosal dissection for large rectal neoplasms. Endoscopy 2016;48:62-70. 